\title{
The Risks of Prolonged Sitting for Motion Graphic Design Office Workers
}

\author{
Ivan Ivan ${ }^{1}$ Julius Andi Nugroho ${ }^{1 *}$ Elina Elina $^{1}$ \\ ${ }^{1}$ Visual Communication Design, Faculty of Art and Design, Universitas Tarumanagara, Jakarta, Indonesia \\ ${ }^{*}$ Corresponding author. Email: juliusn@fsrd.untar.ac.id
}

\begin{abstract}
Office workers on average work for 8 hours a day, sometimes they work overtime and have no choice but to stuck in traffic jams to the point of prolonged sitting. Studies have shown that prolonged sitting might contribute to increasing health risks in diseases that vary from less dangerous to chronic and serious ones. This design aims to provide practical solutions that can be followed by the target audience even in busy schedules. The author used data collecting methodologies such as observation, interviews, literature studies, and questionnaires. Respondents tend to rarely exercise, oftentimes they work overtime, and have a habit of prolonged sitting. The plan is to design a short duration motion graphic, using vectors without outlines with a normal body proportion based on the most chosen choices in the questionnaire, with the use of green and blue inspired by the logo used by the Indonesian Ministry of Health as a color of the theme in the motion graphic.
\end{abstract}

\section{Keywords: Prolonged sitting, Busy, Health Risks, Motion Graphic}

\section{INTRODUCTION}

Modernization has shifted our habit as a society into a sedentary lifestyle, especially by sitting in offices for hours. At the same time, we are also living in the age of capitalism, which means business competitions pressured us to produce goods and services as efficient and as flawless as possible. Based on a questionnaire conducted by the author, the average respondent works for 9 to 5 jobs, and sometimes are given additional hours to fulfill and please costumer's and company's demand. For some people, in order to fulfill these demands, they're supported by technological development, like long-distance travelling simply by sitting on a chair or ordering a good without going outside because it's done online and the ordered goods will arrive to the receiver's requested destination.

Jakarta has been the center of economy for Indonesia, because of its most populated province and its highest GDP in the country. On the other hand, Jakarta also has the tenth worst traffic jam in the world, especially during hours from 6 A.M. and the traffic worsen in the next hours. The worst traffic jam in Jakarta on average is 4 P.M. until 7 P.M. especially on Friday, and the traffic progressively recover as hours goes by.

However, studies have shown the fact that prolonged sitting might contribute to the higher chance of health risks, such diseases might vary from a low, less dangerous diseases like low back pain or deep vein thrombosis, to a serious and chronic diseases such as stroke, dementia, heart diseases, and other types of cancer such as lung cancer, endometrium, or intestine cancer.
Luckily, studies also found a lot of evidences that regular physical activities might help to reduce the risk of such health risks, like avoiding cardiovascular diseases and other types of chronic diseases [1]. One study also shows that there is a connection between decline in immunity, and sedentary behaviors like prolonged sitting [2], and as usual, the intervention of physical activities and regular exercise shows contribution in helping to reduce those risks of declining immune system [3]. However, there's bad news, another study conducted at the University of Regensburg, Germany, concluded that physical activities such as jogging or walking in the morning does not even contribute a significant impact on reducing health risks because the act of prolonged sitting that has been done for too long, fortunately, those risks can be reversed by physical activities that are also carried out in a long term [4].

But the problem is, the solution is not as easy as invites office workers to go jogging or join the gym because everyone can't do it, their busy schedules, and not everyone is good at time management, especially office workers on the age of 30 to 35 years old. Well, the good news is, according to a study done in Queensland, Australia, we can still reduce these health risks simply by taking a "break" from sitting, or interrupting those sitting time. From the study alone, it can be concluded that health risks can be reduced when physical activities such as standing or walking that interrupt sitting time [5].

In urban areas such as Jakarta, we have many workers with a long sitting time that has become very prone to such health risks. The author hoped to focus the motion graphic design, exclusively to a more specific demographic, and that is office workers, because office jobs is one of the most 
occupied jobs in cities. For instance, in Jakarta, most profession taken in 2016 is employee with population of 2,6 million.

According to a government website, in Jakarta, age 30-34 years old have the most workers in the city according to a data conducted in 2019, which is one of the reasons why the author's target audience are 30-35 years old.

\section{BACKGROUND}

This motion graphic design aims to educate office workers using simpler and more memorable messaging. The motion graphic will also provide practical solutions to fight health risks due to prolonged sitting that can be followed even in busy schedules. That way, office workers might have the chance to learn to maintain their health and overcome health risks because of prolonged sitting.

This motion graphic will be supported by a movement supported by the Indonesian government's Ministry of Health, called GERMAS or Gerakan Masyarakat Hidup Sehat (in English, it's Healthy Lifestyle Community Movement), because it's a movement that promotes and persuade the public into healthy habit. The media that will be made are 1:57 minute motion graphic, 30 second ads, and advertisements in Instagram post and story.

\section{METHODS}

\subsection{Methodology of Visual Communication Design}

In the process, there are a few phases for the author to approach in order to create a good quality motion graphic. In pre-production, there are a lot to be prepared by the author, for instance, deciding a topic with a high level of urgency, and looking at everything with support of available information, such as information about the target audience, and information about how important is the topic being selected so people will be able to care about the topic being brought up in the motion graphic. Supporting data that are obtained through interviews, literature reviews, and questionnaires can help to strengthen the message of the motion graphic. The author also plans scenes and sequences through scripts and storyboards in order for efficiency in designing the motion graphic.

Then in production, the author designs vector assets in Adobe Illustrator CC that will be animated inn Adobe After Effects CC.

In the next step, we enter post-production, motion graphics from separate videos will be merged into one in Adobe Premiere Pro CC. Finally, the author will put the narrator's voiceover and also sound effects in order to make the motion graphic more interesting.

\subsection{Method of Collecting Data}

The data collecting method used by the author is mixed because the author uses several methodologies, such as observation, interviews, literature review, and questionnaires.

Qualitative method like observation is done through paying attention to everything that happened to our surroundings and environment, within the scope of research, the data collected should objective and not be biased.

Another qualitative method is interview, which means receiving information directly by asking the experts or people who are relevant in the field. This method is very effective because we can strengthen our credibility and obtain information that are difficult to be discovered in the internet.

Literature review is a qualitative method carried out independently by the author, obtained through journals and scientific studies that have been conducted by experts.

The author also uses quantitative method by sharing questionnaire to the target audiences as respondents. This method relies on the answers and choices chosen or answered by the respondents, and the author will analyze and make conclusion based on the result of the questionnaire.

\subsection{Method of Data Analysis}

Based on SWOT analysis, the author concluded a few key benefits and drawbacks of having motion graphic as a medium for this topic.

From a strength viewpoint, motion graphics with limited duration can give the author an advantage in making a simpler and more memorable messaging, so the audience will not be left confused. Providing information with moving illustrations such as motion graphic can help the audiences understand the premise better. The animations made using interesting and dynamic vectors without looking childish, which can provide as a visual entertainment for the target audiences. Moreover, these types of motion graphics can give the impression of a lighter video making the audiences feel relaxed.

By looking at the strength, we can conclude that the weaknesses of motion graphics are because of their limited duration, the information provided is also limited. Not everyone has access to discover motion graphics. The reach for this motion graphic might decline if the office workers are very busy at the moment. According to the author's data, unconventional media tend to be skipped more often, especially the fact that this motion graphic will be promoted through YouTube Ads.

Technological development can become an opportunity for motion graphic as the author's medium, because the claims provided in motion graphic can be verified easily by the audiences, which strengthen the motion graphic's credibility. Another opportunity for motion graphic as the author's media is, it can be used either as a commercial or an instructional video. Motion Graphics can be supported or supports other mediums for multimedia such as videography or photography. Motion graphics can replace conventional media, and provide as an alternative to articles or news articles with multiple paragraphs. 
Based on the threat the author analyzed, any unusual information given to the target audiences, if they just heard it for the first time might cause skepticism in the audiences. Nowadays, social medias are filled with interesting contents that might cause the audiences less likely to watch the motion graphic, that fact also applies to other motion graphic contents that are more interesting than we think.

The author also analyzed the target audiences through questionnaires and by choosing the target audiences through Geography and Demographics.

\section{FINDINGS AND DISCUSSIONS}

\subsection{Target Audiences}

The motion graphic focuses on people working in Jakarta Special Capital Region in Indonesia, with the average age of 30 to 35 years old in the life stage of adulthood.

The author focuses on both men and women who are working 9 to 5 jobs as office workers, with the socioeconomic status of lower and middle class. In analyzing the target audience, the author forms a questionnaire given to 52 respondents of the age of 30-35 who are working as office workers. From psychographic analysis, the target audiences the author aims are prone to be tired because their mind are filled with thoughts about their work and their business which make them more likely to seek entertaining content during rest. Even despite the fact of prolonged sitting time, a lot of 30-35 years old office workers are aware with the fact that prolonged sitting can cause serious consequences. Based on the author's questionnaire, the respondents prefer flat designs with no outline and normal posture.

Target audiences tend to spend hours working in office, and often times work over times. They also agree with avoiding traffic jams by going home late, they tend to use cars and motorcycles, and sit for an hour for a round-trip, respondents on average rarely exercise. By media consumption, respondents mostly use YouTube and Instagram, some respondents still consume television in decent duration.

\subsection{Key Facts}

Based on the author's data, analysis, and observation, we can emphasize a few facts that we concluded. Although prolonged sitting is not the main cause of various diseases, it is still one of the most supporting cause. According to the interview, people age 30 or above are one of the age that needs to be aware of the risks in prolonged sitting. YouTube ads cannot be skipped until 5 seconds, the author has the chance to attract the target audiences' attention in the first 5 seconds.
Based on the research done, the list of risks for prolonged sitting includes backpain, deep vein thrombosis, muscle weakening, stroke, dementia, decreased in immunity, kidney diseases, heart diseases, and a few types of cancers.

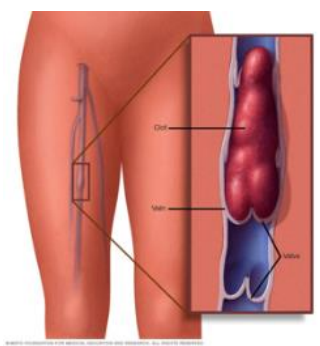

Figure 1 Illustration of deep vein thrombosis (DVT)

However, we can conclude that all diseases and consequences that people got from prolonged sitting, their chances can all be reduced by physical activities, it's important to note that physical activities doesn't necessarily means exercising, it can also mean more walking, and doing stretching. These risks could also be reduced by taking care of diet, and sitting positions.

As an important disclaimer, the solutions the author is going to provide is purposefully for avoiding and reducing health risks caused by prolonged sitting, people that got chronic diseases might be told to do physical activities but requires more treatment from professionals.

In the author's questionnaire that was filled by 52 respondents, most respondents, which are $28.8 \%$ answered that they spent 6 hours per day, $26.9 \%$ respondents answered 8 hours per day, $19.2 \%$ answered 7 hours per day, and $17.3 \%$ answered under 6 hours per day.

In Table 1, the result suggested that respondents spent more hours at the office, and the majority of respondents worked an average of 8-9 hours per day. Respondents also admitted that while in the office, they spent hours sitting.

Table 1 Respondents' work duration

\begin{tabular}{|c|c|c|}
\hline No & Duration / hour & Numbers of respondents \\
\hline 1 & $x<6$ & $3.8 \%$ \\
\hline 2 & 6 & $1.9 \%$ \\
\hline 3 & 7 & $5.8 \%$ \\
\hline 4 & 8 & $50 \%$ \\
\hline 5 & 9 & $2.9 \%$ \\
\hline 6 & 10 & $7.7 \%$ \\
\hline 7 & $10<x$ & $3.8 \%$ \\
\hline
\end{tabular}

The overtime factor may be influenced by respondents who wait for traffic jam hours to pass by spending more time at the office because they don't like being stuck in traffic. In the Table 2, respondents feel that they do not need it because they walk to and from work. 
Table 2 Respondents towards traffic jam hours

\begin{tabular}{|c|c|c|}
\hline No & $\begin{array}{c}\text { Agree/ } \\
\text { Disagree }\end{array}$ & $\begin{array}{c}\text { Numbers of } \\
\text { respondents }\end{array}$ \\
\hline 1 & Agree & $69.2 \%$ \\
\hline 2 & Disagree & $26.9 \%$ \\
\hline 3 & Others & $3.8 \%$ \\
\hline
\end{tabular}

In Table 3, respondents are also more likely to work overtime at the office. The table below explains the scale from $0-10$, how often respondents go home late, and scale 8 is the most followed by scales 7 and 9 , meaning that office workers will sit longer in the process.

Table 3 Respondents' overtime duration

\begin{tabular}{|c|c|c|}
\hline No & $\mathbf{0 - 1 0}$ & Numbers of respondents \\
\hline 1 & 0 (never) & $3.8 \%$ \\
\hline 2 & 1 & $3.8 \%$ \\
\hline 3 & 2 & $5.8 \%$ \\
\hline 4 & 3 & $3.8 \%$ \\
\hline 5 & 4 & $3.8 \%$ \\
\hline 6 & 5 & $13.5 \%$ \\
\hline 7 & 6 & $7.7 \%$ \\
\hline 8 & 7 & $17.3 \%$ \\
\hline 9 & 8 & $21.2 \%$ \\
\hline 10 & 9 & $15.4 \%$ \\
\hline 11 & 10 (very often) & $3.8 \%$ \\
\hline
\end{tabular}

In Table 4, $42.3 \%$ of respondents use motorbikes, $38.5 \%$ use cars, and another $9.5 \%$ use buses. Even though the respondents went home without waiting for the traffic jam, they remained seated around 30 minutes - 1 hour.

Table 4 Respondents' roundtrip duration

\begin{tabular}{|c|c|c|}
\hline No & Duration & Numbers of respondents \\
\hline 1 & $x<30$ minutes & $42.3 \%$ \\
\hline 2 & 30 minutes & $23.1 \%$ \\
\hline 3 & 1 hours & $23.1 \%$ \\
\hline 4 & 2 hours & $5.8 \%$ \\
\hline 5 & 3 hours & $1.9 \%$ \\
\hline 6 & 3 hours $<\mathrm{s} x$ & $1.9 \%$ \\
\hline 7 & Others & $1.9 \%$ \\
\hline
\end{tabular}

In Table 5, it can be shown that respondents also tend to rarely exercise on average, with the highest scale being 2 to 3 according to the questionnaire, both of which amounted to $17.3 \%$, and scale 5 was $15.4 \%$. This is the target audience the author wants to aim at, and as a reason for the author to provide a simple solution that can be implemented by the target audience.

Table 5 Respondents' exercise frequency

\begin{tabular}{|c|c|c|}
\hline No & $\mathbf{0 - 1 0}$ & Numbers of respondents \\
\hline 1 & 0 (never) & $13.5 \%$ \\
\hline 2 & 1 & $9.6 \%$ \\
\hline 3 & 2 & $17.3 \%$ \\
\hline 4 & 3 & $17.3 \%$ \\
\hline
\end{tabular}

\begin{tabular}{|c|c|c|}
\hline 5 & 4 & $5.8 \%$ \\
\hline 6 & 5 & $15.4 \%$ \\
\hline 7 & 6 & $5.8 \%$ \\
\hline 8 & 7 & $9.6 \%$ \\
\hline 9 & 8 & $3.8 \%$ \\
\hline 10 & 9 & - \\
\hline 11 & 10 (very often) & $1.9 \%$ \\
\hline
\end{tabular}

In Table 6, respondents were allowed to choose more than one options, and in the following result, most respondents use YouTube and Instagram, which is the reason the author uses both platforms as a medium for promotions.

Table 6 Most used social media by the number of responses

\begin{tabular}{|c|c|c|}
\hline No & Social Media & Numbers of respondents \\
\hline 1 & YouTube & $76.9 \%$ \\
\hline 2 & Instagram & $92.3 \%$ \\
\hline 3 & Facebook & $48.1 \%$ \\
\hline 4 & Twitter & $17 \%$ \\
\hline
\end{tabular}

The author also places supporting media on TV commercials, because according to Table 7 , the watching duration of TV viewers aged 30-35 years still tends to be moderate. Scale 8 was the most with the age of $21.2 \%$, followed by scale 7 with $17.3 \%$ and scale 5 with $13.5 \%$.

Table 7 Respondents' TV consumption

\begin{tabular}{|c|c|c|}
\hline No & $\mathbf{0 - 1 0}$ & Numbers of respondents \\
\hline 1 & 0 (never) & $15.4 \%$ \\
\hline 2 & 1 & $19.2 \%$ \\
\hline 3 & 2 & $7.7 \%$ \\
\hline 4 & 3 & $11.5 \%$ \\
\hline 5 & 4 & $9.6 \%$ \\
\hline 6 & 5 & $7.7 \%$ \\
\hline 7 & 6 & $7.7 \%$ \\
\hline 8 & 7 & $1.9 \%$ \\
\hline 9 & 8 & $7.7 \%$ \\
\hline 10 & 9 & - \\
\hline 11 & 10 (very often) & $11.5 \%$ \\
\hline
\end{tabular}

In Table 8, the illustrations that are used in the author's work are the result of a questionnaire distributed and according to the results, respondents tend to prefer a more realistic vector design, as seen from the questionnaire results where $71.2 \%$ of respondents prefer flat designs without lines or borders. Around $55.8 \%$ of respondents also prefer design with thin outline and $25 \%$ prefer design with thick outline.

Table 8 Respondents' flat design preferences

\begin{tabular}{|c|c|c|}
\hline No & Flat design types & Numbers of respondents \\
\hline 1 & No outline & $71.2 \%$ \\
\hline 2 & Thin outline & $19.2 \%$ \\
\hline 3 & Thick outline & $9.6 \%$ \\
\hline
\end{tabular}




\subsection{The Concept and Creative Strategy}

\subsubsection{Creative Strategy}

The author determines the duration of the main media, namely 1:57 so that the audience does not get bored watching the video. The concept used by the writer is relaxing, fresh and simple. Relaxing in the sense of using colors that are refreshing to the audience, namely using the blue color from the Ministry of Health logo and using green, these two colors are also one of the most frequently used colors in medical design.

The simple concept is intended so that the motion graphics does not feel heavy, not only seen from its limited duration, but also the flat design style and background that tend to be plain, as well as an easy-to-understand manner for most people.

Then the author made supporting medias such as 30 second ads, an Instagram story and post, so people will click on it and have them brought to the main media.

\subsubsection{Creative Concept}

\subsubsection{Keywords}

The keywords for the motion graphic is simple, fresh and relaxing. In order to fit the taste of a tired target audience post working.

\subsubsection{Idea}

The general idea is to give office workers a simple advice on a problem that they have to care about, it is better than to tell them to run in the morning every day because not everyone is able do that. With simple and fresh-toned visuals can make the audience to feel relax while watching the motion graphic.

\subsection{Creative Decision}

\subsubsection{Verbal Decision}

Firstly, for the narration, the author decided to use a feminine voice as a voice over in the main media, because it sounds softer and preferable for health topic.

Secondly, the approach is to make the audience relate with the character in the motion graphic, and tell the problem that's generally faced by most office workers, and one of them is prolonged sitting, then we tell them the consequences of those actions, finally we give them the most practical solution we can find that can be easily implemented by the target audience.

\subsubsection{Visual Decision}

The entire motion graphics are going to be made with normal proportion and no outlines, just like what the majority of respondents prefer. The motion graphic was created with a focus on a main character named Udin, in order to make him look like an Indonesian, the author gave him brown skin and black hair.

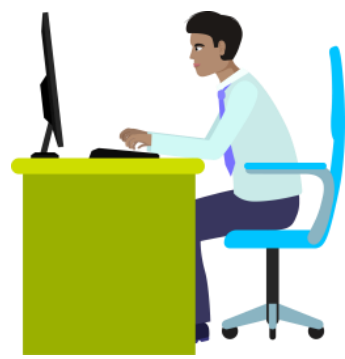

Figure 2 Vector / Animation of Udin typing

First, the writer creates a vector of Udin typing in his desk, by designing all his body parts separately in Adobe Illustrator CC that will later be animated in After Effects CC. The author starts from making Udin's typing animation, and put it in the IG Story, one of the supporting medias, then keeps it as an asset to be used later in the remaining medias. To make the motion graphics look simpler, the author used the same office background on each media, sometimes only using a plain background with the color according to the color palette, and the same position, namely Udin who always faces towards the left. The office background is a large printer, another table with a computer and a window with a view of the building, which emphasizes the office background, the background color is made monotonous so that the audience can focus on the main character.

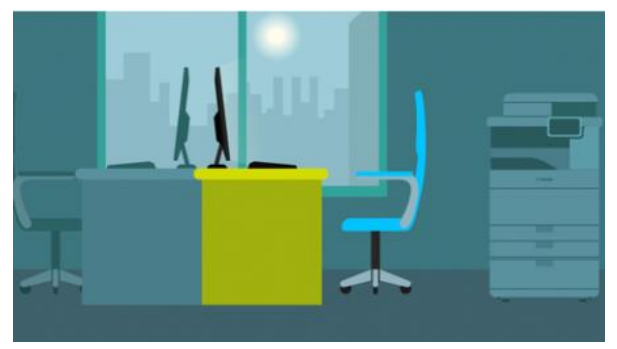

Figure 3 Motion graphic's office

The color palette that the author's uses to emphasize the theme according to the keywords, the author used yellow and blue inspired by the logo of the Indonesian Ministry of Health, and then a bright green and darker blue of the brighter blue before. The purpose of using a color palette is to maintain the consistency of the themes raised by motion pictures.

Color also plays an important role in providing a fresh, relaxing theme, for instance, green and blue are associated with health themes [6], and green can refresh the audiences' eyes, making the video a pleasant sight even for busy office workers. 


\section{\#d2dc02 \\ \#afffoo \\ \#16b3ac \\ \#3d767f}

Figure 4 Color palette

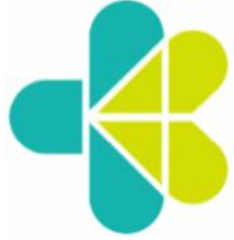

\section{KEMENTERIAN}

KESEHATAN

REPUBLIK

INDONESIA

Figure 5 The logo of Indonesian Ministry of Health

The type of font used is Volkswagen, because the font has curved corners which suit the health topic and is used as a typeface on the Ministry of Health logo, so that it is suitable for health themes.

While Volkswagen is used a typeface in the motion graphic, Futura font can be used as a font that blends in with the vectors that presented as objects in the motion graphic.

\section{Futura \\ Volkswagen-Bold}

Figure 6 Fonts used in the motion graphic

\subsubsection{Media Decision}

The author made 4 medias, but technically 5 medias, the first one being a motion graphic with a duration of 1:57 minutes with a size of $1920 * 1080 \mathrm{px}$.

The second one is a motion graphic promotion in form of YouTube ads and TV commercials with a duration of 30 seconds each with a size of $1920 * 1080$ px.

The next one is an Instagram story with a duration of 8 seconds with a frame size of $1080 * 1920$ px and an Instagram post with size $1080 * 1080 \mathrm{px}$

\subsection{Design Media}

\subsubsection{Main Media}
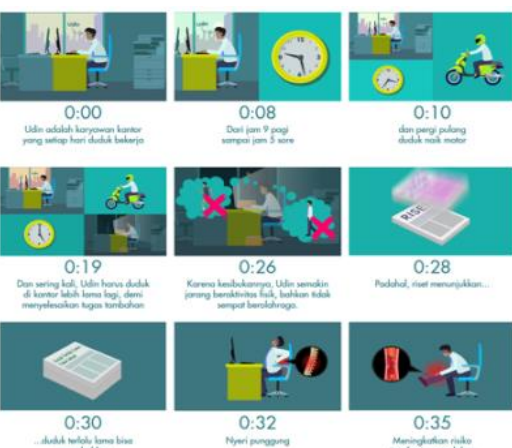

$0: 28$
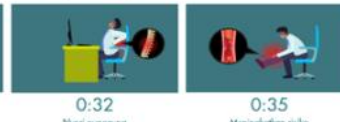

$0: 32$

$0: 35$
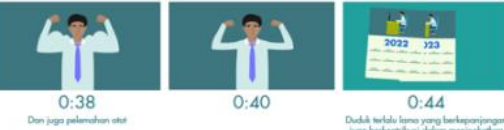

Figure 7 Main media part 1
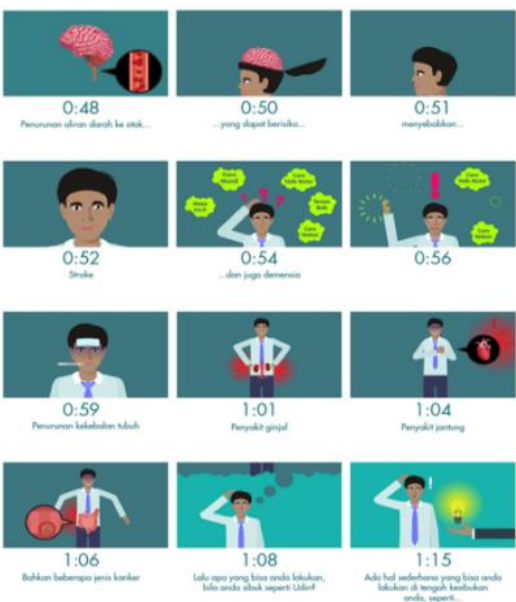

Figure 8 Main media part 2

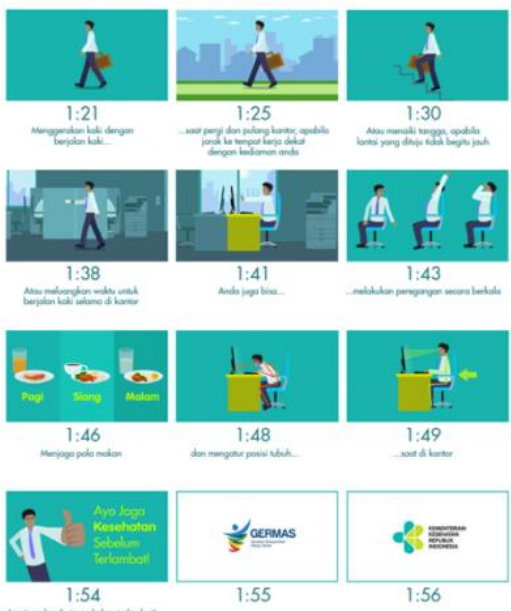

Figure 9 Main media part 3 


\subsubsection{Thirty-Second Ads}
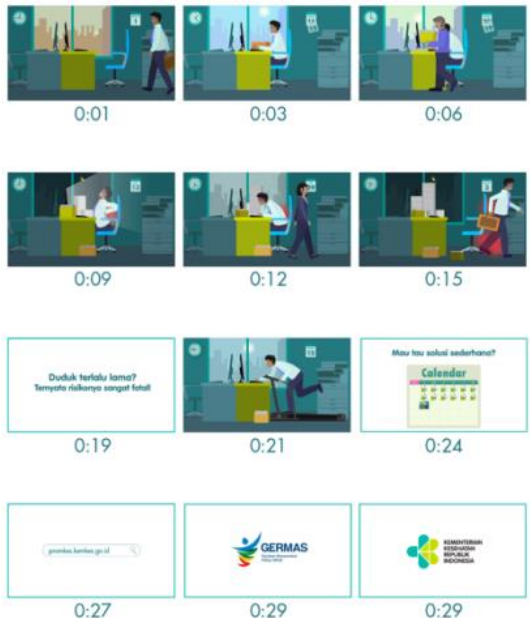

Figure 10 Thirty-second ads

\subsubsection{Instagram}
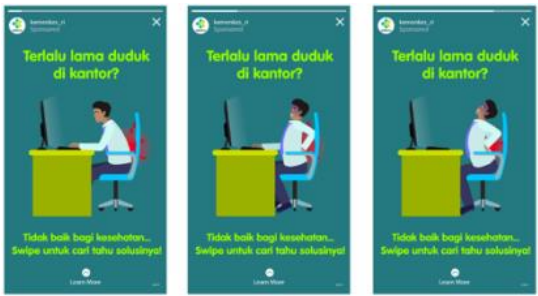

Figure 11 Instagram story

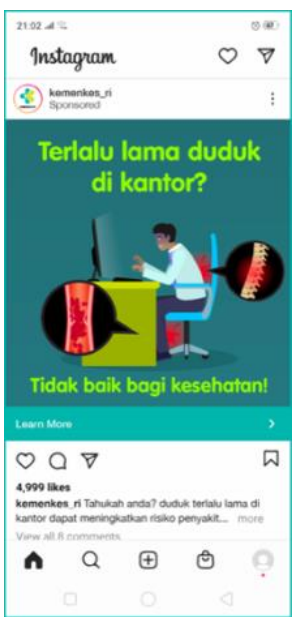

Figure 12 Instagram post

\section{CONCLUSIONS}

There are many office workers with no time to exercise, because many of them feel their schedules and busyness at work prevents them to do it. Therefore, the author designed a motion graphic that educates office workers about the risks of sitting for a long time and provide it's prevention by providing practical solutions they can follow, using simple and memorable approach

The purpose is to create a motion graphic with a limited duration, and vectors without outlines with normal body proportions. The author also uses green and blue colors inspired from the logo of Indonesian Ministry of Health as one of the main colors for the motion graphic theme.

This research explores health topics that can be beneficial to the general public. Although many people recognize the risks of prolonged sitting, many are don't have decent information in how to prevent it.

The drawback of this research is that the author had difficulty understanding some of the content of scientific papers and medical journals, which is why the author asked an expert for help to understand certain medical journals.

Recommendations for future research are to choose topics that are not only of interest, but also understood. But what is no less important is the ability to design certain media.

\section{ACKNOWLEDGMENT}

This work was supported through scientific journals and studies that were conducted by multiple institutes in multiple countries. Much gratitude goes to Doctor Vinisia Setiadji, M.Ked (ClinPath), Sp.PK, for her willingness to spend time and conduct an interview with the author, as well as helping the author in understanding a few medical journals that are better understood by doctors, and also to the questionnaire respondents who have been willing to spend their time to assist the author in quantitative data collecting.

\section{REFERENCES}

[1] Warburton, D. E. R., \& Bredin, S. S. D. (2019). Health Benefits of Physical Activity: A Strengths-Based Approach. Journal of Clinical Medicine, 8(12).

[2] Allison, M. A., Jensky, N. E., Marshall, S. J., Bertoni, A. G., \& Cushman, M. (2012). Sedentary behavior and adiposity-associated inflammation: The Multi-Ethnic Study of Atherosclerosis. American journal of preventive medicine, 42(1), 5.

[3] Nurmasitoh, T. (2015). Physical activities, exercises, and their effectss to the immune system. Jurnal Kedokteran dan Kesehatan Indonesia, 7(2), 57.

[4] Newman, H. (2016, November 2). Exercise doesn't reverse the harm of being sedentary and sitting all day. Quartz. https://qz.com/223160/why-not-even-exercise- 
will-undo-the-harm-of-sitting-all-day-and-what-you-

can-do-about-it/

[5] Mackie, P., Weerasekara, I., Crowfoot, G., Janssen,

H., Holliday, E., Dunstan, D., \& English, C. (2019).

What is the effect of interrupting prolonged sitting with frequent bouts of physical activity or standing on first or recurrent stroke risk factors? A scoping review. PloS one, 14(6), 20.

[6] Pinch Studio. (n.d.). The logo colors of healthcare. 99designs.com. https://99designs.com/logo-design/ psychology-of-color/healthcare 